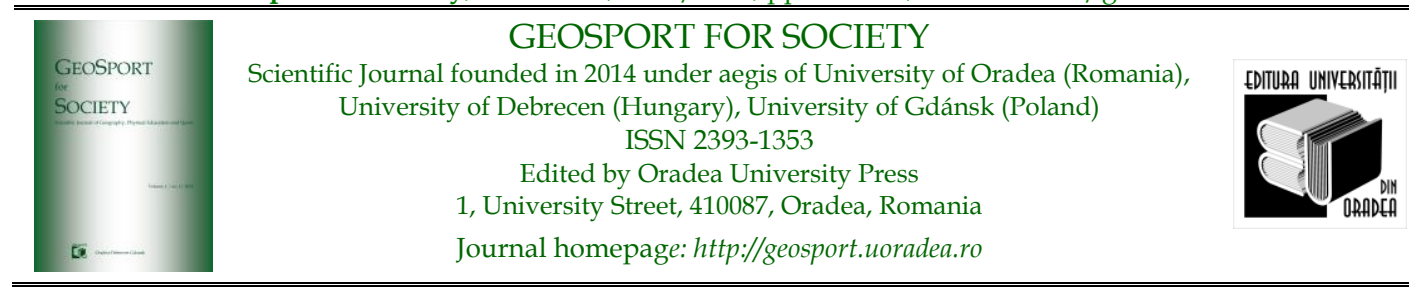

\title{
Essential Aspects of Beach Volleyball Technique
}

\author{
Gabriel Alexandru PETROVICI ${ }^{*}$
}

1. University "1 December 1918" Alba Iulia, Faculty of Law and Social Sciences, Department of Physical Education and Sport, Str. Gabriel Bethlen, No. 5, Alba Iulia, C.P. 510009, Romania, e-mail: ducu petrovici@yahoo.com

* Corresponding author

Citation: Petrovici, G.A. (2020). Essential Aspects of Beach Volleyball Technique. Geosport for Society, 13(2), 131-139. https://doi.org/10.30892/gss.1304-063

Article history: 20.08.2020; Revised: 24.09.2020; Accepted: 10.11.2020, Available online: 20.11.2020

\begin{abstract}
Beach volleyball is a sports game practiced during performance sports activities and people who love to move, or for recreational purposes, Loisir. The game of beach volleyball resembles the game of indoor volleyball in terms of the similarity of essential execution by the volleyball player and some actions of attack or defense. However, the two sports also have significant differences. This is making beach volleyball one of the most famous and practiced sports, especially in the hot season. Also, statistics highlight that sports with the ball up in the open air have the most massive audiences among the sports practiced at the Summer Olympics.
\end{abstract}

Keywords: beach volleyball, technique, beach volleyball fundamentals

\section{Introduction}

The volleyball game is an acyclic team game, where muscular work is of a speedpower, accuracy-coordinating character (Kozina et al., 2018). The volleyball game has developed in speed and strength characteristics, being physical (Sopa, 2019).

Beach volleyball is a sports game practiced during performance sports activities and people who love to move, or for recreational purposes, Loisir. The game of beach volleyball resembles the game of indoor volleyball in terms of the similarity of essential execution by the volleyball player and some actions of attack or defense. However, the two sports have also significant differences. This is making beach volleyball one of the most famous and practiced sports, especially in the hot season. Also, statistics highlight that sports with the ball up in the open air have the most massive audiences among the sports practiced at the Summer Olympics.

Volleyball games, relatively simple, once, by training players and multilateral actions' scroll speed, get to enjoy a wide increasingly accepted by the audience (Cojocaru and Cojocaru, 2018). The game of volleyball has a wide range of actions in 
the game, from the simplest to the most complex. This required the players to continue training and persevering and staging the sequence of processing the learning and teaching for coaches, which gives a touch of increased subtlety of this game (Szabo, 2015). A volleyball player's use of explosive power in vertical, horizontal, and side movements is critical (Sopa, 2019).

Volleyball has become one of the most practiced sports in the world (Herman et al., 2018). The volleyball game requires expertise in several physical fitness and performance and often depends on an individual's ability to jump on very high-level parameters (Szabo, 2015).

As games become more balanced, there is a greater need to understand whether winning teams are better at putting into practice the skills of playing more points or making fewer mistakes (Szabo et al., 2018).

Performance in collective sports is mirrored by a series of inter-relational components, in the middle of a complex universe where there are various phenomena expressed through general and specific systemic relationships that act synergistically to achieve sporting performances (Szabo et al, 2019).

One of the main reasons why beach volleyball is so famous and increasingly popular around the world is that unlike indoor volleyball, where a player specializes in a particular position, he will carry out specific training only for that activity, in beach volleyball, a player must master all the elements and technical procedures encountered. Thus, in the game of beach volleyball, a player must have an excellent command of the following elements: service, receiving, setting the ball for the attack with an overhand pass or a forearm pass, attack, blocking, recovering the ball with or without diving, while in indoor volleyball a player can only specialize for setting the ball, attacking and blocking the ball, and there is even the possibility of not serving at all.

In indoor volleyball, a player can be a reserve and can do nothing but hope that he will be used in the team by changing a starting player, and if this does not happen, he will have to overcome this psychological impasse and prepare for the next match. Beach volleyball is an intermittent team sport played by two teams of two players on a sand court divided by a net (Kiraly, 1999). It is characterized by frequent high-intensity efforts interposed by short recovery phases (Palao et al., 2012). The performance involves jumps (e.g. attacking, serving, blocking), short sprints, direction changes, and diving digs (Natali et al., 2017). During a single set, Palao et al., (2012) observed that defenders and blockers performed an average of 27 and 31 jumps, respectively. Also, moving on sand increases energy costs compared to moving on the solid ground (Zamparo, 1992).

Beach volleyball is played under demanding environmental conditions: Zetou et al., (2008) reported that during over 50 matches analyzed in an official tournament, the mean air temperature was $33.6^{\circ} \mathrm{C}\left(\max 38^{\circ} \mathrm{C}\right)$, and mean humidity was $56 \%$ (max 75\%). While there are no changes in beach volleyball, a player has to cover a much larger area of the gym than in indoor volleyball, reaching to touch the ball more often, almost every time it is in their part of the court. For this aspect, the players need an excellent physical condition, jumping from sand being much more massive than the ones in the gym; they require specific physical training among the 
athletes, the muscular strength development training carried out in a gym getting a special significance.

Beach volley game is divided into two phases: side out and counter attack. The sequence of beach volleyball actions is: serve, serve reception, set, attack, block, and dig (George and Panagiotis, 2008). The side out phase includes: serve reception, setting, and attack. The counterattack includes: block, dig, set, and attack (Costa et al., 2012).

In beach volleyball over the years, with its changes to the rules, the athlete should fundamentally provide good physical strength, such as speed (reaction and displacement), agility, explosive power, and maximum force (Bizzocchi, 2008; Lehnert et al., 2009; Pereira et al., 2015; Pastore et al., 2015).

Beach volleyball is less harmful to the players' body integrity; it does not put so much pressure on the ligaments and joints, as a big advantage it can be practiced until a considerable age. In beach volleyball, there is a significant amount of landings following jump movements related to high forces in the lower limb joints (Bisseling et al., 2007; Edwards et al., 2012; Lindner et al., 2012). Such high forces may cause acute and overuse injuries like anterior cruciate ligament ruptures or patellar tendinopathies, respectively (Bahr and Reeser, 2003).

In beach volleyball, each of the competitors needs to know their role during the point dispute. Thus, when the player hits the ball at service, the players must know exactly what they have to do in the next phase, and the two must have a game plan from the very beginning regarding who will receive the service. Usually, if the players are at the same quality level of the game, each occupies $50 \%$ of the court. If one player is more valuable than the other, he occupies $60 \%$ of the court; the other will cover only $40 \%$. If the age difference is significant between the two partners, one of them being a player over 45-50 years old, the more mobile player will cover $75 \%$ of the field in the receiving position.

\section{Setting the ball in beach volleyball}

Once the ball has left the receiver's hands, his teammate must already be set in the middle of the field and wait for the ball to be set for the player's attack that received the ball from service. There are two types of setting for attacking (lifting): setting the ball with two hands from above - the overhand pass, or setting with two hands together, from a lower position - the forearm pass. A good player must master both. Beach volleyball players often use the forearm instead of the overhand pass because of the risk of a technical error due to an incorrect movement, although the overhand pass is more precise (Koch and Tilp, 2009). Hernandez et al., (2004) analyzed the kinematics of the overhand pass in indoor volleyball; however, kinematic analysis of the overhand pass in beach volleyball lacks. A good setter will be able to put the ball in the attacking position no matter where it bounces from the colleague's hand after receiving the ball from service, and for this, the setter must have the ability to execute the following technical elements in the following order:

1. Deciphering the opposing defense: the setter must study very quickly how to prepare the opposing defense to play the next offensive phase. Depending on how the opponents are arranged, the setter must decide in a short time where he will send the ball for the attack. 
In beach volleyball, the efficacy of the reception is high. In nine out of ten receptions, the execution allows the team to build an attack (Lacerda and Mesquita, 2003; Lopez et al., 2009). The reason for this is probably the difficulty of moving in the sand, in addition to communication problems in the zone between the receivers (Noël et al., 2016; Smith, 2006).

2. Receiving anticipation: To execute the setting for attack, the setter must be very careful in the direction that the ball gets after executing the receiving by his colleague. Ideally, the receiving will be a perfect one, and the ball will get a direct trajectory to the place where the setter is located. It happens very often that the receiving is less successful or even wrong, and then the setter must be prepared for a swift move, because when he comes in contact with the ball to be in a firm position, static so he has the best chance of sending the ball to where his partner wanted it to go. Reception analysis should consider the type of service and, if possible, the serve speed (Busca et al., 2012; Palao and Valades, 2014).

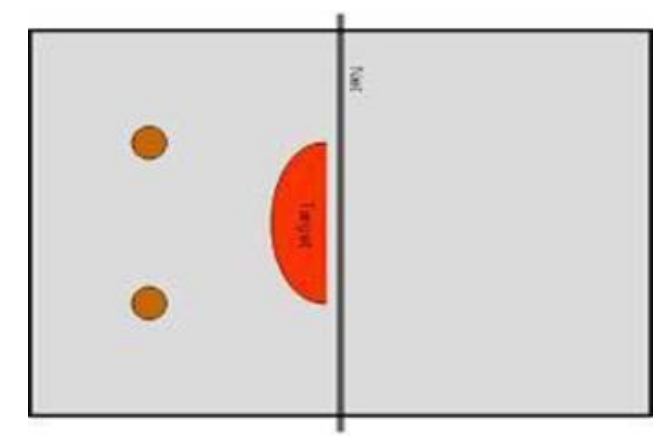

Figure 1. Receiving zone from the opponent service

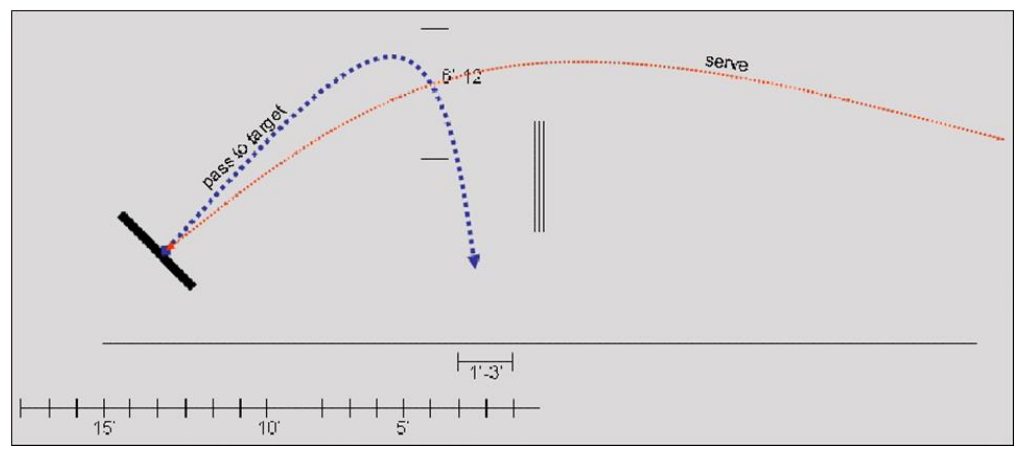

Figure 2. Perfect receiving of the service

3. Entering a stable position (planting): like in the case of the receiving position, in this case, a swift movement of the setter is needed so that he positions itself on the downward trajectory of the ball (with the hope that it will land in the target area desired by both players). The feet must firmly be embedded in the sand to give a solid base to the absolute position which requires the legs to be apart shoulder width, the knees bent, the body bent forward so that it can efficiently 
perform a vertical movement to come into contact with the ball quickly or sometimes even to make a jump in order to prevent the ball from passing over the net following an imperfect receiving. Emphasis is placed on the use of leg muscles, and of course, special attention is needed on the ball that should not be overlooked at any time. The footwork is an essential aspect in order to prepare the correct execution position of the setting (Tilp and Rindler, 2013). The shoulders should be close to the net, forming an ideal angle of 90 degrees, so that the ball can be easily sent both forward and backward, and the foot that is closest to the net should be placed approximately $10-15 \mathrm{~cm}$ further than the one from the center of the court.

4. Bending the legs: if a setting is used (as in most cases) with the overhand pass, the legs must be bent at the beginning of the movement to execute the ball set for the attack. This aspect makes the overhand setting, which differs from the one used with the forearm pass, to be precise, strong enough and sent exactly where the teammate wants it. The force gives the power with which the ball leaves the setter's hand that the legs develop at the moment of their extension when returning from flexion. The hands are the ones that apply the direction on the ball in particular and not the force on it, only to a minimal extent (D'Anastasio et al., 2019).

5. The actual setting of the ball: it has reached the stage where the ball is in a downward trajectory, the body is positioned just below it, and it is observed that the ball has much rotation around its axis, in addition to the downward movement that we anticipate. At this point, in order not to make a mistake, namely double contact on the ball, much prior preparation is needed. The training is essential both for receiving, attack, and physical training and for the ball set. The palms are positioned in the form of volleyball, and the movement that the setter will perform is to push his hands towards the ball, thus canceling the effect received by the ball after reception of the ball. Therefore, the forearms should be bent at the elbow joint and positioned with the palms just above the forehead, with the thumbs oriented parallel and opposed to the eyes of the setter who will set the ball to his attacking colleague. A rapid movement positions the body under the ball's downward trajectory resulting from receiving the ball with the hands positioned so that if it did not hold them in this position, the ball would hit the setter exactly in the forehead.

6. Target zone: First of all, related to this aspect, we have to determine which the targeted area for setting the ball is. The easiest way to pass the ball is in front, hoping that the teammate also synchronizes with the ball and moves properly for the attack. As the game level increases, the setter must reach the stage where he can accurately set the ball both forward and backward, sideways, by jumping or in any way that serves his teammate effectively for his team. In principle, the ball must reach a trajectory parallel to the net at a distance of about $0.5 \mathrm{~m}-0.75 \mathrm{~m}$ in front of the attacking teammate.

If the attacking player is left-handed and plays on the left side of the court, the setting for him must be in the position where he is or a little to the outside, but not to the inside of the court as his chances of attacking the ball from the setting decrease dramatically. If the attacker is right-handed and plays on the left side, that is considered his substantial area the setting can be sent without problems either in 
front of the attacking player or further inwards if it cannot be entirely controlled, but not outwards.

It is much easier to attack an attacker who is on his strong side if the setting is more inwards than outwards. In the mirror, if we have a left-handed player who plays on the right side (his strong side), he adapts more quickly to a ball that comes inwards than one that passes him, and the trajectory carries him outwards. If a player activates on his weak side (a right-hander on the right or a left-hander on the left), the pass must be set either in front of them about the position in which they evolve or outside the antenna area.

Another important aspect concerns the setting's height and how it can be quantified in a well-defined way. Of course, we cannot give a very exact answer for this aspect, but it is clear that the ball, after being set, must rise at least 1 meter above the height of the net (if the players are close in that phase and the attacker can hit the ball before it falls below the top strip of the net). If the distance between the two teammates is considerable, the setting's height must increase considerably, and the ball should rise in the air at about 2 meters, as the attacker needs more time to reach the optimal position of attack and court orientation towards the opposing team. Both partners must start with the same thought, namely: it is never the setter's fault for a wrong attack. An attacker should adapt to any setting he receives from the setter, and in no way is he allowed to blame the coordinator. This should be noted because there is no framework in which the attacking player is immortalized in world-class tournaments when he blames the setter for the wrong setting. Billy Ashen, head coach at the University of California, said that "True attackers adapt to the setting regardless of its type".

\section{Mental preparation in beach volleyball}

Particular importance should be given to mental dispute in a game of beach volleyball. There are two types of mental disputes: the dispute between the two opposing teams and each player's dispute with himself. It is evident that in a sports dispute, whether it is a match in a competition or a simple, friendly match, all players want to win that dispute.

It is a behavior studied in many specialized works, and it is a majority concluded that no athlete likes to lose. Of course, there are no athletes who have not known defeat, but the way a player behaves when he loses or wins a game, a set or a point, differentiates them into two categories.

Experts believe that an athlete who is rational, sober in his actions, and mood externalizations and inner feelings have much better chances of progress, assertion, and long-term gain. When an athlete manifests himself in a pronounced way after winning a point, he expresses himself beyond measure, it is a sign that opponents often interpret as simple luck for him, and if he were to play that same type of attack or defense again, the chances of success would be lower. It puts the success to the sign of doubt and on the luck in such situations.

On the other hand, when one of the players expresses his frustration very openly after a point or a lost match, he is considered vulnerable by the opponents for the following actions and will try to take advantage of this aspect. Also, a very 
vocal player, very exteriorized, is not very pleasant even by the spectators; they want to see a balanced and neutral person in behavior on the court regardless of the recorded result.

At a high level, in official FIVB, World Tour, or AVP competitions, this type of extreme behavior is sporadic, to the surprise of amateurs who observe so-called highly contested and won by individual players, to the surprise of fans they do not show their joy very obviously winning the point. This aspect is to be avoided by athletes and considering that every action of this kind is accompanied by energy consumption, which against the background of accumulated fatigue, and the difficult conditions in which this sport is played can make a difference.

\section{Conclusions}

Beach volleyball practiced from an early age opens up opportunities to practice volleyball, including in the gym in the coming years. More and more sports organizations and clubs are tempted to organize beach volleyball competitions, as the demands among athletes and spectators continue to grow with representation. Many specialists consider that a beach volleyball player can evolve in indoor volleyball and do it at a satisfactory level, but for an indoor volleyball player, it is not very easy to move to beach volleyball because the gym is far too specialized for each position. The best volleyball players started their careers on the sand and then switched to indoor volleyball. In other research with same interdisciplinary character highlighted the importance of children's psychomotor level (Szabo et al., 2020a) and the young population's health level (Szabo et al., 2020b; Szabo and Sopa, 2020a; Szabo and Sopa, 2020b).

\section{References}

Bahr, R., \& Reeser, J. C. (2003). Injuries among world-class professional beach volleyball players: the Federation Internationale de Volleyball beach volleyball injury study. The American journal of sports medicine, 31(1), 119-125.

Bisseling, R. W., Hof, A. L., Bredeweg, S. W., Zwerver, J., \& Mulder, T. (2007). Relationship between landing strategy and patellar tendinopathy in volleyball. British journal of sports medicine, 41(7), e8-e8.

Bizzocchi, C. (2008). 0 voleibol a alto nível: da iniciação à competição. 2ed. Barueri, SP: Manole.

Buscà, B., Moras, G., Peña, J., \& Rodríguez-Jiménez, S. (2012). The influence of serve characteristics on performance in men's and women's high-standard beach volleyball. Journal of sports sciences, 30(3), 269-276.

Cojocaru, A. M., \& Cojocaru, M. (2018). The model of the middle blocker in volleyball. LUMEN Proceedings, 5(1), 80-87.

Costa, G. C., Afonso, J., Brant, E., Mesquita, I. (2012). Differences in game patterns between male and female youth volleyball. Kinesiology, 1, 60-66

D’Anastasio, R., Milivojevic, A., Cilli, J., Icaro, I., Viciano, J., D’Anastasio, R., ... \& Viciano, J. (2019). Anthropometric profiles and somatotypes of female volleyball and beach volleyball players. Int. J. Morphol, 37(4), 1480-1485.

de Faria Pastore, J. C., de Azevedo Ferreira, C. A., da Costa, F. C. H., \& Joao, P. V. (2015). Case Study: Proposal for Training in Combined Plyometrics and Muscular Strength in Improved Vertical Jump in Beach Volley. International Journal of New Technology and Research, 2(5), 30-33.

Edwards, S., Steele, J. R., Cook, J. L., Purdam, C. R., McGhee, D. E., \& Munro, B. J. (2012). Characterizing patellar tendon loading during the landing phases of a stop-jump task. Scandinavian journal of medicine \& science in sports, 22(1), 2-11. 
George, G., \& Panagiotis, Z. (2008). Statistical analysis of men's FIVB beach volleyball team performance. International Journal of Performance Analysis in Sport, 8(1), 31-43.

Herman, G. V., Szabo-Alexi, M., Szabo-Alexi, P., Dragoș, P. F., \& Marinău, M. (2018). The sport, vector of regionalization/globalization Case study: International Volleyball Federation (FIVB). GeoSport for Society, 9(2), 88-95.

Hernandez, E., Urena, A., Miranda, M. T., \& Ona, A. (2004). Kinematic analysis of volleyball setting cues that affect anticipation in blocking. Journal of Human Movement Studies, 47(4), 285-301.

Kiraly, K. (1999). Shewman, B.Beach Volleyball. Human Kinetics: Champaign, IL, USA.

Koch, C., \& Tilp, M. (2009). Beach volleyball techniques and tactics: A comparison of male and female playing characteristics. Kinesiology: International journal of fundamental and applied kinesiology, 41(1), 52-59.

Kozina, Z. L., Goloborodko, Y. A., Boichuk, Y. D., Sobko, I. M., Repko, O. O., Bazilyuk, T. A., ... \& Osiptsov, A. V. (2018). The influence of a special technique for developing coordination abilities on the level of technical preparedness and development of psycho-physiological functions of young volleyball players 14-16 years of age. Journal of Physical Education and Sport, 18(3), 1445-1454.

Lacerda, D., \& Mesquita, I. (2003). Analysis of the offensive process on the side out in elite beach volleyball. Digital Journal. www. ef. deportes. com/Buenos Aires, 61(9).

Lehnert, M., Lamrová, I., \& Elfmark, M. (2009). Changes in speed and strength in female volleyball players during and after a plyometric training program. Acta Gymnica, 39(1), 59-66.

Lindner, M., Kotschwar, A., Zsoldos, R. R., Groesel, M., \& Peham, C. (2012). The jump shot-A biomechanical analysis focused on lateral ankle ligaments. Journal of biomechanics, 45(1), 202-206.

Lopez-Martínez, A. B., \& Palao, J. M. (2009). Effect of serve execution on serve efficacy in men's and women's beach volleyball. International Journal of Applied Sports Sciences, 21(1), 1-16.

Natali, S., Ferioli, D., La Torre, A., \& Bonato, M. (2017). Physical and technical demands of elite beach volleyball according to playing position and gender. The Journal of sports medicine and physical fitness, 59(1), 6-9.

Noël, B., Hüttermann, S., van der Kamp, J., \& Memmert, D. (2016). Courting on the beach: how team position implicitly influences decision-making in beach volleyball serves. Journal of Cognitive Psychology, 28(7), 868-876.

Palao, J. M., \& Valades, D. (2014). Serve speed peaks in FIVB World Tour beach volleyball (20052012). Acta Kinesiologica, 8(2), 7-10.

Palao, J. M., Valades, D., \& Ortega, E. (2012). Match duration and number of rallies in men's and women's 2000-2010 FIVB world tour beach volleyball. Journal of Human Kinetics, 34(1), 99-104.

Pereira, A., M Costa, A., Santos, P., Figueiredo, T., \& Vicente João, P. (2015). Training strategy of explosive strength in young female volleyball players. Medicina, 51(2), 126-131.

Smith, R. (2006). Movement in the sand: Training implications for beach volleyball. Strength and Conditioning Journal, 28(5), 19-21.

Sopa, I. S. (2019). Developing attack point in volleyball game using plyometric exercises at 13-14 years old volleyball players. Bulletin of the Transilvania University of Brasov. Series IX, Sciences of Human Kinetics, 12(2), 67-76.

Szabo D. A., Neagu N., Ardelean M., Sopa I, S. (2020a). Psychomotor evaluation of athlete and nonathlete children, Discobolul - Physical Education. Sport and Kinetotherapy Journal, 59(1), 56-69. https://doi.org/10.35189/dpeskj.2020.59.1.6

Szabo D. A., Neagu N., Stoica B. A., Fodor D., Sopa I., S. (2020b). Analytic study regarding physical development and health level at youth population aged between 10 and 15 years old. Studia UBB Educatio Artis Gymn, LXV(2), 39 - 54. DOI:10.24193/subbeag.65(2).13

Szabo D.A., \& Sopa I., S. (2020b). Study regarding the bio-motor level and health of children from gymnasium level. Interdisciplinary Journal of Physical Education and Sports, 20(1), 1-9.

Szabo, D. A. (2015). Modalities of using the information provided by the statistical program click and scout for improving the outside hitters' service efficiency in volleyball game. The European Proceeding of Social \& Behavioral Sciences EpSBS, 341-347.

Szabo, D. A., Neagu, N., Teodorescu, S., Sopa, I. S. (2018). Modalities of exploatation the information provided by the Click \& Scout statistical program in preparing volleyball attack players. International Journal of Applied Exercise Physiology, 8(21), 852-859. 
Szabo, D. A., Neagu, N., Voidazan, S., Sopa, I. S., \& Gliga, C. A. (2010). Analyzing the attack players in volleyball through statistical methods. Health, Sports \& Rehabilitation Medicine, 154-158. DOI: 10.26659/pm3.2019.20.4.154

Szabo, D.A., \& Sopa, I. S. (2020a). Study regarding the level of physical and functional development of children from primary school level. Journal of Physical Education and Sport, 20(3), 1497-1504. Doi: 10.7752/jpes.2020.03206

Tilp, M., \& Rindler, M. (2013). Landing techniques in beach volleyball. Journal of Sports Science \& Medicine, 12(3), 447-453.

Zamparo, P., Perini, R., Orizio, C., Sacher, M., \& Ferretti, G. (1992). The energy cost of walking or running on sand. European journal of applied physiology and occupational physiology, 65(2), 183-187.

Zetou, E., Giatsis, G., Mountaki, F., \& Komninakidou, A. (2008). Body weight changes and voluntary fluid intakes of beach volleyball players during an official tournament. Journal of Science and Medicine in Sport, 11(2), 139-145. 